\title{
The occurrence of Trilasmis kaempferi (Cirripedia, Lepadomorpha) in the Rockall Trough on a previously unrecorded host, Neolithodes grimaldi (Decapoda, Anomura)
}

\author{
R. Williams \\ Department of Zoology, University College of Swansea, Swansea, Wales
}

Species of the genus Trilasmis (five-plated lepadids) are all epizoic on large decapod Crustacea. T. kaempferi (Darwin, 1851) has previously been described from several hosts but never on Neolithodes. In September, 1983, over 1000 specimens of this barnacle were collected from the Rockall Trough in a single haul of a semi-balloon otter-trawl at a depth range of $1540-1550 \mathrm{~m}$, at $56^{\circ} 33^{\prime} \mathrm{N}$, $09^{\circ} 40^{\prime} \mathrm{W}$ to $56^{\circ} 42^{\prime} \mathrm{N}, 09^{\circ} 34^{\prime} \mathrm{W}$ during a cruise by R.R.S. Challenger. They were attached to the carapace and limbs of the deep-sea anomuran Neolithodes grimaldi Milne-Edwards \& Bouvier (1895), a spiny stone crab. This is the most northerly record of $T$. kaempferi and only the second report of it from the Atlantic, the first being from the Azores.

Of the twenty-three live $N$. grimaldi in the sample, five did not carry barnacles or other epizoites, no doubt having recently moulted. Some loose crabs' legs in the haul were moulted exoskeleton, but still supported live $T$. kaempferi when sampled. The size/frequency distribution of $T$. kaempferi was determined on four crabs but revealed no distinct size (age) classes in the population. There was a direct relationship between crab size and the largest of its epizoic barnacles (Fig. 1)_presumably as a result of less frequent moulting of older crabs.

A study of the distribution pattern of barnacles on the crabs revealed:

1. On carapaces more barnacles were settled on the anterior halves.

2. On the carapace and abdomen the majority of barnacles were attached to spines, whereas on the crabs' legs they were in the angle at the base of the spine.

3. On the carapace and abdomen most barnacles were situated posteriorly on the vertical spines but on leg spines, which are all directed anteriorly at angles of $30^{\circ}-60^{\circ}$, were in anterior positions. Therefore the barnacles inhabit the most protected sites on the crab.

4. Barnacles located on spines were approximately halfway between the base and tip of a spine, which could be the result of either selective settlement or elimination.

5. The barnacles were most densely crowded on the crabs' legs.

6. The settlement pattern was non-random, which could be due to heterogeneities in the crabs' surface, but is more likely to result from gregariousness exhibited by the cyprid at settlement.

7. The orofices (and therefore cirri) of the majority of barnacles were facing the surface of the crab.

General examination revealed oocytes in $43 \%$ of barnacles from a minimum length of $5 \mathrm{~mm}$. The oocytes were surrounded by yolk in $10-19 \mathrm{~mm}$ barnacles. There was no oocyte development in barnacles below $5 \mathrm{~mm}$ in length, which 

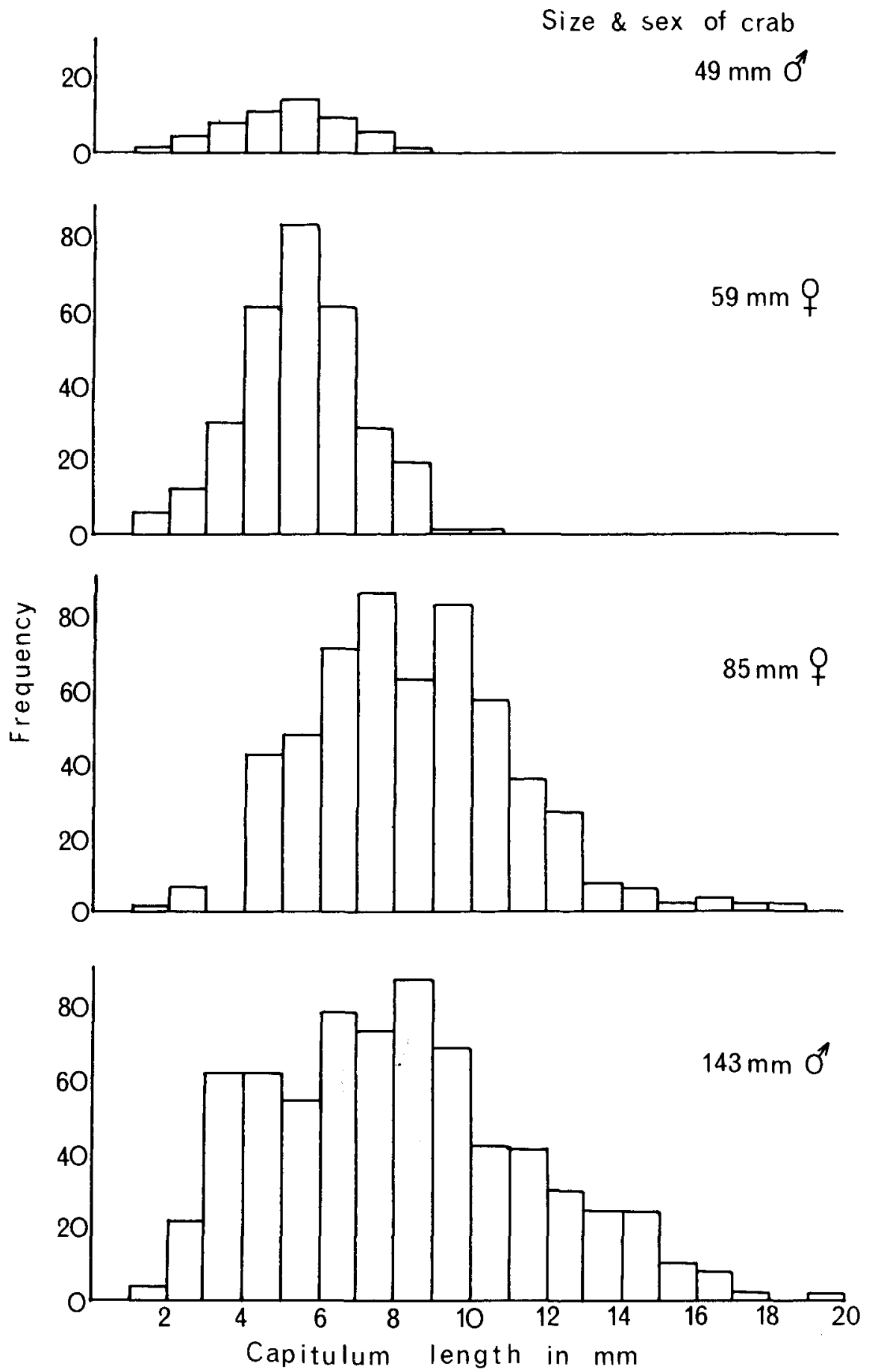

Figure 1. Size/frequency distributions of the barnacle, Trilasmis kaempferi, on different sized males and females of the crab, Neolithodes grimaldi. No obvious size classes are evident to indicate different age groups in the population. 
presumably had not reached sexual maturity. Only one barnacle $(10 \mathrm{~mm})$ contained ripe egg lamellae.

No other hauls from the Rockall Trough have yielded examples of this partnership. This phoretic association presumably affords $T$. kaempferi protection without disadvantaging the crab.

\section{Post-larval morphology of some northwest European ophiuroids}

\section{Webb}

Department of Oceanography, University College, Swansea SA2 8PP, Wales

The early post-larval development of ophiuroids, in general, follows a similar pattern of disc and arm plate morphogenesis. Adult characteristics are developed at some stage in this period, but often well beyond metamorphosis. The transient post-larval morphology present in this intervening period, often differing markedly from subsequent stages, has generally poorly known taxonomic, ontogenetic and functional significance. A brief survey of the dorsal disc and arm morphology in the smallest free-living and settled post-larvae of a variety of N.W. European representatives of the order Ophiurae (Ophiura ophiura, O. albida, O. ljungmani, Ophiocten gracilis, Ophiomusium lymani, Acrocnida brachiata, Amphiura filiformis, A. chiajei, Amphipholis squamata, Ophiocomina nigra and Ophiacantha bidentata) serves to highlight and explore these aspects. The use of Scanning Electron Microscopy (SEM) proves invaluable in resolving such features.

Primary plate stereom is an intriguing early post-larval feature that may prove to have significance at various taxonomic levels. For example, a distinctive stereom of a regular pattern or round, craterlike fenestrations extending to the plate edge, is observed in the three Ophiura species examined and appears to be confined to the genus. Similarly the rounded pentagonal central primary plate and rectangular terminal plate may be other generic features.

Another plate stereom observed is the bordered type observed in Acronida brachiata, Amphiura filiformis and Ophiocten gracilis. In Acronida with $0.4-0.6 \mathrm{~mm}$ discs, the thicker central region has an open latticework while the region bordering the plate edge is thin, having its fenestrations partially infilled. Variations of this bordered plate stereom occur in the other two species, but in all cases such borders are confined to the primary plates. Other features of plate development are specific, such as the fenestration size in Ophiura or the unique spined stereom of Ophiomusium lymani. The functional and adaptive value of ophiuroid primary plate morphology is generally unknown.

The nature of the terminal plate of the recently-metamorphosed post-larva exhibits greater variation between closely-related species, as do other aspects of arm development (i.e. arm segment number, spine form and equality of growth), whose adaptive and functional value may be more readily seen. That allied species with similar adult ecological habit remain distinguishable, may suggest that 